\title{
ORTEGA Y GASSET Y LA CRÍTICA DE LA RAZÓN CIENTÍFICA
}

\author{
Alba Milagro Pinto \\ I.E.S. Virgen de Vico (Arnedo, La Rioja)
}

RESUMEN: En este artículo se expone la cuestión de la ciencia en el pensamiento de Ortega y Gasset desde su fundamentación metafísica de la vida como realidad radical. De este modo, la crítica a la razón científica se articula en tres ámbitos interconectados: a) Ciencia-filosofía: el cambio en la concepción del ser como nuevo objeto de la ciencia y de la filosofía. b) Ciencia-historia: las implicaciones históricas de la ciencia como creencia fundacional de la razón moderna. c) Ciencia-símbolo: la función simbólica de la ciencia como interpretación teórica de la circunstancia humana. Estas tres variantes de la reflexión convergen en un mismo interés: analizar las implicaciones filosóficas que la creencia en la razón científica ha tenido y tiene en la estructura general de la vida humana.

Palabras clave: Crisis de la modernidad, razón científica, filosofía de la ciencia, Ortega y Gasset, razón histórica.

ABSTRACT: This article analyses the conception of science in Ortega y Gasset's thought in terms of his metaphysical foundation of life as radical reality. Thus, the critique of scientific reason encompasses three interconnected areas: a) Science-philosophy: the change in the conception of Being as a new object of science and philosophy. b) Science-history: the historical implications of science as a foundational belief of modern reason. c) Science-symbol: the symbolic function of science as a theoretical interpretation of the human circumstance. These three types of reflection converge on the same interest: to analyze the philosophical implications that the belief in scientific reason has had in the structure of human life.

Keywords: Crisis of modernity, scientific reason, philosophy of science, Ortega y Gasset, historical reason. 


\section{Introducción}

El interés de Ortega por la ciencia' atraviesa toda su producción intelectual. Se trata de un tema recurrente del que siempre parte y al que siempre llega, y en ese camino va forjando su propia concepción de la realidad. ¿Qué es la ciencia y qué la filosofía?, ¿cuál ha sido el desarrollo histórico de la razón científica?, ¿de dónde viene y a dónde nos lleva la crisis de la racionalidad científica? A pesar de ser éste un tema menor, es posible tomarlo como hilo de Ariadna que nos guíe hasta el corazón de la metafísica orteguiana y nos permita tejer una imagen de la ciencia acorde con su compleja filosofía. Ortega escribió sobre la naturaleza, objeto, método, lenguaje, presupuestos, resultados e historia de la ciencia, pero no encontramos en su obra algo así como una «filosofía de la ciencia». Sobre esta cuestión comparto la opinión de Luis García Aguilar según la cual «Ortega es un filósofo, a secas, y no cabe presentarle como un precursor o protodescubridor de los hilos conductores de esa disciplina particular. Su reflexión acerca de los fundamentos de la Naturaleza y de toda actividad humana, se sitúa por debajo de cuestiones particulares, como pueden ser la metodología o los lenguajes lógicos, siendo su objeto la implicaciones filosóficas de la ciencia»².

Ortega es un filósofo, a secas. Esto quiere decir que el lugar de la ciencia en el pensamiento orteguiano está ligado a su propia concepción de la filosofía. Ortega medita sobre la ciencia para llegar a la filosofía y desde la comprensión omniabarcadora de ésta restablece los límites de la ciencia para que recupere su sentido al servicio del hombre del siglo XX. Desde esa perspectiva aparece la reflexión sobre la ciencia que se matiza en tres aspectos fundamentales. a) Ciencia-filosofía: el problema del conocimiento y el estatuto de la filosofía frente al saber científico. b) Ciencia-historia: las implicaciones históricas de la ciencia como creencia fundacional de la razón moderna. c) Ciencia-símbolo: la función simbólica de la ciencia como interpretación teórica de la circunstancia humana. Estas tres variantes de la reflexión convergen en un mismo interés: analizar las implicaciones filosóficas que la creencia en la razón científica ha tenido y tiene en la estructura general de la vida humana.

1. Como el lector sabrá, el término ciencia equivale etimológicamente a «saber». Ciencia es episteme, conocimiento riguroso y objetivo. Así pues, la historia de la ciencia es la historia de la cultura. Y no será hasta el siglo XVI cuando una rama del saber se independice del resto con un método y objeto diferenciado y se atribuya en exclusiva el título de "ciencia». Así pues, tenemos dos sentidos -ligados históricamente- para este término: 1. ciencia como saber objetivo y riguroso y 2. conocimiento de lo empíricamente mensurable (en especial la Física). En este artículo debemos atender a su doble significación, esperamos que el contexto en cada caso aclarare la sinécdoque del uso común.

2. García Aguilar, L. «La ciencia en el pensamiento de Ortega. Ensayo sobre la influencia de la ciencia en la evolución del pensamiento orteguiano», Endoxa, Series filosóficas, n 7, 1996, UNED, Madrid, p. 258. 
Aunque el propósito de este artículo es analizar la concepción orteguiana de la ciencia, al acercarnos a la lógica orteguiana enseguida constatamos que esta cuestión es sólo el preámbulo de una sucesión de temas encadenados que van desde la crítica a la modernidad hasta una original concepción del ser. Así pues, el objeto de este estudio queda desplazado del concepto ciencia a la relación de la meditación sobre este tema con su concepción genuinamente filosófica de la realidad en los tres ámbitos que acabamos de mencionar. Para abordar esta cuestión en primer lugar y antes de adentrarnos en los vericuetos del pensamiento orteguiano situaré la cuestión de la ciencia en la filosofía y en la biografía intelectual de Ortega y Gasset. El segundo punto de este artículo nos llevará al corazón mismo de su metafísica, allí detendremos nuestra atención en algunas nociones fundamentales de la filosofía de Ortega que son imprescindibles para comprender el alcance de su meditación sobre la ciencia. En el tercer epígrafe nos ocuparemos de la relación ciencia-historia; revisaremos brevemente el análisis y crítica de la razón moderna desde el punto de vista del nacimiento y desarrollo de la ciencia. Y en el cuarto punto veremos la relación ciencia-símbolo a través de la valoración que Ortega hace de la ciencia de su tiempo en correspondencia con su pensamiento filosófico.

Como decía unas líneas más arriba, el interés de Ortega por la ciencia aparece a lo largo de toda su obra, y claro está, su percepción de la ciencia se va forjando a la par que su propia filosofía. En los primeros años de formación alemana (1905-1913) encontramos una concepción de la ciencia ${ }^{3}$ en la que confluyen los aires regeneracionistas de la España de principios de siglo con el idealismo neokantiano aprendido en Marburgo. En este sentido, podemos ver cómo en un temprano texto de $1906^{4}$ Ortega se maravilla de la buena salud y disciplina de la ciencia alemana y francesa donde el Saber es una institución que va más allá de los individuos concretos que en ella trabajan, mientras que en España ha habido algunos hombres de ciencia, sí, pero no hallamos una Ciencia. En esta etapa, para Ortega Europa equivale a Ciencia y esa es la solución para España. Por esa razón hará suya la misión de insuflar algo de ciencia en el alma española y proyectará a lo largo de su vida diversas empresas editoriales que traduzcan al español las principales obras científicas del momento. Siguiendo este empeño se crea en 1913 la Liga de Educación Política española que tiene como fin una labor pedagógica de formar hombres de ciencia que sean la simiente de la nueva ciencia española.

A partir de 1913, aproximadamente, Ortega se desvincula del neokantismo y se aproxima a la fenomenología. El objetivismo cultural y la concepción sal-

3. En este caso "ciencia" equivale a cultura, no se refiere al conocimiento empírico.

4. 1906 La ciencia romántica, I, p. 86-91. Se cita el pensamiento de J. Ortega y Gasset por la edición de sus Obras Completas. Fundación Ortega y Gasset-Taurus, Madrid. 2004-2010. Se indica el número del tomo en romanos y el número de página en arábigos. 
vífica de la ciencia del periodo anterior se ven sustituidas por una visión mucho más vitalista que revaloriza el mundo real y huye del subjetivismo idealista. El análisis de la crisis de la racionalidad científica a la luz de la razón vital deja patente que la ciencia está relegada a un segundo lugar frente a la vida. La idea clave de esta etapa, que se mantendrá a lo largo de toda su obra, es que para superar el idealismo imperante en los últimos tres siglos, la «razón pura» debe subordinarse a la razón vital. La vida no es un método de conocimiento sino al contrario, el conocimiento es un instrumento de la vida. La ciencia, pues, es sólo un subproducto de la razón al servicio de la vida, un fenómeno vital como lo es el arte, la religión o la nueva moda en el vestir. En 1923 sentencia que el tema de nuestro tiempo es la superación del idealismo, y el camino para conseguirlo es totalmente fenomenológico: ir a las cosas mismas, no pretender imponer nuestros esquemas a priori, sino adecuar nuestros conceptos a lo que la realidad nos muestra de sí misma. "La razón pura no puede suplantar a la vida: la cultura del intelecto abstracto no es, frente a la espontánea, otra vida que se baste a sí misma y pueda desalojar aquella. Es tan sólo una breve isla flotando sobre el mar de la vitalidad primaria. Lejos de poder sustituir a ésta, tiene que apoyarse en ella, nutrirse de ella como cada uno de los miembros vive del organismo entero ${ }^{5}$. En un apéndice a El tema de nuestro tiempo titulado El sentido histórico de la teoría de Einstein, Ortega expresa su entusiasmo por la nueva ciencia inaugurada por Einstein y ve en la teoría de la relatividad la confirmación de su propia filosofía ${ }^{6}$. Ortega está convencido de que la nueva ciencia del siglo XX ha suscitado un giro copernicano en la interpretación del hombre y del universo: la razón ya no es el tribunal ante el cual la realidad rinde cuentas, es la vida la que discrimina la adecuación de las teorías sobre ella. Se han invertido los términos, los conceptos se han puesto al servicio de la vida. Parafraseando a Kant podemos decir que la vida sin orientación es ciega, y la razón, si no es vital, está vacía. Por lo tanto, el positivismo científico ya no tiene cabida, es el tiempo de la razón vital.

En la llamada por él mismo «segunda navegación» que se produce al filo de 1929 encontramos un viraje de la razón vital hacia la razón histórica. Como afirma el profesor Lasaga, encontramos «una "primera navegación" en la que Ortega ensaya una filosofía centrada en la diferencia vida/cultura, pensada desde la categoría central del sujeto, pensado a la manera kantiana, y orientado hacia una antropología filosófica capaz de ampliar el sujeto idealista de la razón pura. Dicho sujeto sería el hombre como una totalidad no escindida en cuerpo y espíritu o sensibilidad y razón. La "segunda navega-

5. 1923 El tema de nuestro tiempo, III, p. 591.

6. Ibíd, p. 614n. En el mismo año de la publicación de El tema de nuestro tiempo. Ortega tuvo la ocasión de intercambiar su parecer con Einstein quien visitó España para dar una conferencia en la Residencia de Estudiantes que fue presentada y traducida por el filósofo madrileño. 
ción" se iniciaría cuando Ortega cae en la cuenta de que dicha búsqueda no escapa al error idealista al buscar fundamentar sobre una realidad cósica o substancial» ${ }^{7}$.

El paso de la razón vital a la razón histórica implica un giro en la concepción de la realidad radical: se abandona el enfoque antropológico y biologicista del hombre-vida como ente sustancial y se profundiza en un nuevo concepto metafísico de vida como ejecutividad. La vida sigue siendo la realidad radical, pero no se interpreta como un compuesto de «yo» y «circunstancia»: es «un tipo de realidad sui generis, metafísicamente anterior e independiente de sus dos componente: sujeto o yo / mundo o circunstancia, los cuales son ingredientes de esa primera realidad: mi vida o la vida de cada cual $\aleph^{8}$. La antropología vitalista de los años veinte se va transformando en la década de los treinta en una metafísica de la vida humana.

No es por casualidad que al tiempo que coge forma su filosofía madura, encontremos numerosos textos en los que se reflexiona sobre el estatuto, método y resultados de la ciencia frente a la filosofía ${ }^{9}$. En En torno a Galileo (1933), Ideas y creencias (1940) e Historia como sistema (1940) aparece formulada definitivamente la filosofía madura de Ortega y su correspondiente visión de la ciencia que analizaremos en los apartados 3 y 4 . El pensamiento de Ortega se gesta frente al espejo de la modernidad y en ese sentido la razón histórica nace como respuesta a los excesos de la razón moderna que es una razón científica e idealista. Como veremos más adelante, la crítica de Ortega al idealismo es una crítica a la ontología tradicional. La innovación metafísica de Ortega implica un giro copernicano respecto a la forma tradicional de entender el ser: Ortega vio claramente que tanto el realismo como el idealismo habían errado en su búsqueda de la realidad radical porque asumían que «ser», «sujeto», «objeto», «verdad» eran entidades cerradas y dóciles a la abstracción conceptual. La hazaña de Ortega consistió en proponer un nuevo modo de entender la realidad y nuestro propio pensamiento desde categorías abiertas y flexibles. La razón vital o histórica implica una reforma de la inteligencia que permite abarcar la realidad radical en toda su complejidad.

7. J. Lasaga Medina. «Los nombres de una filosofía: razón vital o razón histórica», Revista de Occidente, no 293 (2005), Madrid, p. 11.

8. Ibíd, p. 18.

9. La concepción sobre la realidad radical del Ortega maduro adquiere consistencia en un periodo aproximado de cinco años, muchos de los textos que encontramos entre 1928 y 1933 tienen en común la reflexión sobre el estatuto de la filosofía frente a la ciencia: 1928 ¿Qué es la ciencia, qué la filosofía?, 1929 ¿Qué es filosofía?, La vida como ejecución. 1930 Sobre la realidad radical, Vicisitudes en las ciencias, ¿Por qué se vuelve a la filosofía?, La rebelión de las masas, ¿Qué es la vida? 1931 ¿Qué es el conocimiento? 1932 Principios de metafísica según la razón vital, Goethe desde dentro. 1933 En torno a Galileo. 


\section{Nociones fundamentales de la filosofía orteguiana}

Como ha advertido Isabel Ferreiro en un reciente artículo: en la obra de Ortega «se encuentra un pensamiento complejo, esto es, una filosofía fiel a la realidad, integradora de todas sus partes, pese a lo distintas y hasta contradictorias que éstas sean; por tanto, un pensamiento coordinador de discrepancias, abierto y capaz de incorporar cuanta gradación y matiz se da en la, a su vez, abierta e ilimitada diversidad que la realidad presenta $\aleph^{10}$. Desde la fidelidad a la realidad, la razón vital se nos presenta como un movimiento incesante en el que la consistencia de lo real se va entretejiendo por la mutua implicación de sus términos también en movimiento: yo-mundo, ensimismamiento-alteración, ideascreencias, temporalidad-eternidad, trascendencia-inmanencia, razón-vida, individuo-sociedad... En este sentido, podemos afirmar que toda la obra orteguiana está construida, tanto en lo que respecta al contenido como en la forma, desde una perspectiva dialéctica. La filosofía de Ortega tiene como objetivo comprender la relación entre los distintos elementos que componen el universo, entre ellos, la ciencia. Por esta razón no es posible mostrar el análisis orteguiano de la razón científica de forma aislada y es preciso decir unas palabras generales sobre el fondo filosófico desde el cual se medita el fenómeno científico.

Lo primero que debemos advertir es que para pensar y hablar desde este nuevo enfoque es necesario desasirnos de las categorías metafísicas tradicionales que expresan siempre conceptos estáticos, atemporales, definitivos, idénticos a sí mismos. Porque nuestro vivir es precisamente lo contrario a eso: es un vivir dinámico, poroso, temporal y circunstanciado. De ahí que una de las grandes preocupaciones de Ortega fuese encontrar un lenguaje apropiado para hablar de la vida.

Frente a la epistemología tradicional -ya sea realista o idealista- que entiende que «sujeto», «objeto», «conocimiento», «razón» y «verdad» son categorías sustanciales y cerradas, la filosofía de Ortega desarrolla estos términos desde la relacionalidad y actividad propia de la razón vital. No se trata, pues, de conceptos cerrados sino que, al ser fruto de una continua construcción vital, necesitan ser entendidos como términos abiertos y dinámicos. Durante veinticinco siglos la filosofía y la ciencia han fundamentado su búsqueda de la verdad sobre las categorías eleáticas del Ser. Esta intelectualización del ser se ha extendido a todos los ámbitos de la realidad: el Hombre, la Verdad y la Razón han sido considerados correlatos del Ser y por tanto igualmente inmutables, eternos y estáticos. Su naturaleza o esencia ha quedado fosilizada en el concepto, el cual refleja el significado general, la forma sustancial e invariable de lo que la cosa es. Así, cuando nombramos la palabra hombre, vida o mundo, el pensamiento

10. I. Ferreiro Lavedán. «Una lectura compleja para un pensamiento complejo.» Revista de Occidente, no 353 (2011) Madrid, p. 113. 
busca aquellos caracteres de fijeza, estabilidad y actualidad que nos permiten entender todo hombre, vida y mundo al margen de su específica temporalidad. Sobre este presupuesto metafísico se ha erigido la civilización occidental. Pero Ortega siente con claridad que en su presente esos cimientos han revelado ser arenas movedizas. "Ha llegado la hora de que la simiente de Heráclito dé su magna cosecha»" advierte el filósofo madrileño. Tengamos la valentía de tomar la realidad tal y como se presenta y hablemos del hombre desde su plasticidad, «mediante conceptos que anulen su propia e inevitable identidad ${ }^{12}$, mediante «conceptos ocasionales» que aseguren la no-identidad constitutiva de aquello que significan. "Porque verdad ha de entenderse no como cosa muerta, según veintiséis siglos de habituación, ya inercial, nos lo hace hoy entender, sino como un verbo - "verdad" como algo viviente, en el momento de lograrse, de nacer; en suma, como acción $»^{13}$.

Para nosotros, dirá Ortega, la verdad es siempre un camino, una perspectiva de la que no podemos zafarnos. Estamos obligados a ensayar verdades y ponerlas a prueba, a bracear incesantemente para mantenernos a flote en el naufragio que constituye nuestra vida. Vemos así, que las categorías clásicas del conocimiento pierden su sustantividad y se convierten en un entramado de relaciones que se va construyendo dialécticamente en un proceso vital e histórico.

\subsection{La vida como realidad radical}

«Se invita, pues, a ustedes para que pierdan el respeto al concepto más venerable, persistente y ahincado que hay en la tradición de nuestra mente: el concepto de ser. Anuncio jaque mate al ser de Platón, de Aristóteles, de Leibniz, de Kant y, claro está, también, al de Descartes» ${ }^{14}$. La crítica de Ortega al idealismo lleva consigo la propuesta de su superación: tanto el realismo como el idealismo partían del hecho de que el ser, lo real, es lo absoluto cerrado e independiente, de tal modo que para el realismo antiguo la realidad radical es el mundo entendido como una sustancia de esencia invariable e independiente del pensamiento y para el racionalismo lo real es el pensamiento independiente del mundo. Ambos enfoques son incorrectos y adolecen de la misma falta de perspectiva: la realidad radical no es absolutamente independiente y acabada sino que consiste en la mutua interdependencia del yo y el mundo. "Yo» $y$ «mundo» no son conceptos cerrados y absolutos sino que van fluyendo uno en otro entretejiendo así la historia.

11. 1941 Historia como sistema, op. cit., VI, p. 66.

12. Ibíd. p. 67.

13. 1943 Epílogo de la Filosofía, op. cit., IX, p. 618.

14. 1929 ¿Qué es filosofía?, op. cit., VIII, p. 335. 
$\mathrm{Al}$ igual que ocurre con esta hoja de la que yo no puedo separar su blancura si no es en mi mente -esto lo aprendimos del hilemorfismo aristotélico-, así ocurre con el «yo»y el «mundo»: ambos se me dan al mismo tiempo y su distinción es mera teorización. La realidad es que ni el yo puede darse independientemente del mundo ni el mundo existe independiente del yo. Tanto el hombre antiguo como el moderno han vivido desde ficciones onto-epistémicas: sujeto y objeto considerados como realidades independientes son meras abstracciones. En un nuevo movimiento dialéctico, Ortega supera el idealismo al tiempo que conserva la verdad que hay en él y en el realismo. El realismo era un puro fuera, pura trascendencia del mundo sin sujeto, el idealismo por su parte es la pura imanencia en la que la realidad acaba convertida en un producto de la subjetividad. La tesis de Ortega y Gasset pone la vida como realidad radical, vida como la coexistencia mía con las cosas. La vida es al mismo tiempo trascendencia e inmanencia.

El imperativo de autenticidad que mueve la reflexión orteguiana implica, frente al idealismo, la aceptación de lo real. Y esto no es ni más ni menos que la aceptación de la propia vida tal y como aparece. La pregunta por la vida se desvela como la cuestión metafísica más genuina, puesto que el vivir es el horizonte del ser. Todo lo que es, acontece en mí vida. Los caracteres de esta nueva realidad radical que es la vida son entre otros: el absoluto acontecimiento, la circunstancialidad, la ejecutividad, la reflexividad, el absoluto incondicionado o la unicidad $^{15}$. Estas características tan crípticas se aclaran al analizar los componentes de la vida: el yo y la circunstancia.

Ambos elementos interactúan dialécticamente en el acontecer de mi vida: el yo es un proyecto a realizar que constituye el perfil de mi circunstancia como conjunto de facilidades o dificultades de un determinado tipo. Pero al mismo tiempo, la circunstancia es aquello que se me enfrenta y el medio en el que yo debo ejecutar mi vocación.

\subsection{El yo y el mundo}

Ortega repite una y mil veces que el hombre no es su cuerpo, ni es su alma, cuerpo y alma son ya elementos de la circunstancia en que me encuentro y con los que tengo que contar para llevar a cabo el programa de mi propia vida. A diferencia de otros seres a los que su ser les viene dado y éste actúa sobre su vida, el hombre tiene que ganarse metafísicamente la vida. En el hombre el ser y el existir no coinciden, es un ser excéntrico que está llamado a ejecutar su programa vital en la alteridad de la circunstancia: la vida del hombre es pura

15. Véase el exhaustivo análisis de las categorías de la vida en A. Rodríguez Huéscar. La innovación metafísica de Ortega. Biblioteca Nueva, Madrid, 2002. 
actuación. Dicho de otro modo: el hombre es «novelista de sí mismo» y «constructor de mundos».

El hombre es un ser indigente que carece de esencia y por ello necesita un plan de acción para vérselas con las cosas, necesita un mapa del mundo para operar en él, para vivir. El problema es que la realidad por sí misma no nos ofrece este mapa, nos encontramos en ella en la pura alteridad y multiplicidad. La circunstancia desnuda es la pura incertidumbre, pero ésta rara vez presenta ante nosotros su faz: la «circunstancia» aparece al hombre ya como «mundo interpretado», como facilidad o dificultad en función de un proyecto vital. Para vivir, el hombre necesita habitar la circunstancia en la que se encuentra, hacerla mundo gracias al esfuerzo de la razón, que le proporciona esquemas provisionales sobre los que construir su vida. El mundo es un tejido de ideas y creencias. No es un ser objetivo, substante y cosificado sino un ser ejecutivo o pura actuación en mi que posibilita/obstaculiza mi quehacer vital. El mundo, pues, es el «conjunto de creencias vigentes en cada momento». La circunstancia es el escenario de nuestra vida, pero el mundo es el decorado con el que cada cual tiene que inventar el argumento. «Vivir es reaccionar a la inseguridad radical construyendo la seguridad de un modo, o, con otras palabras, creyendo que el mundo es de éste o del otro modo, para en vista de ello dirigir nuestra vida, vivir» ${ }^{16}$.

El hombre no sólo es «constructor de mundos», también es «novelista de sí mismo». El «yo», por tanto, tampoco es una sustancia cerrada, es una elección que el hombre hace en cada instante de su vida. Debemos inventar/descubrir/ intuir un proyecto vital y ponerlo en práctica. Este proyecto no nos es dado ni es definitivo, lo ideamos en función de las circunstancias y las creencias en que estamos. Cada uno de nuestros actos y decisiones actualiza nuestra imagen del mundo y de nosotros mismos. Pero llega un momento en que este proyecto descubre sus limitaciones y ya no nos sirve, debemos reinventarnos sobre la base de los «yoes» que ya fuimos. Paradójicamente tenemos la necesidad de elegir libremente nuestro yo, pero nuestra decisión no es arbitraria; estamos llamados a hacer de la libertad destino. El ideal de autenticidad exige de nosotros que seamos fieles a nuestra vocación y a nuestra circunstancia pero no poseemos un acceso a priori a nuestro fondo insobornable del que brota la vocación. Nos descubrimos a nosotros mismos en nuestro quehacer en el mundo, ejecutando ya un programa vital que se va configurando mediante ensayo y error.

"Yo»y «mundo» no son estantes cerrados sino que son expresión de la ejecutividad del propio acto de vivir. No es posible pensar el yo separado de las cosas ni las cosas al margen del yo. Debemos pensar en ellos como conceptos ocasionales en permanente interacción, son dos aspectos inseparables «que refle-

16. A. Rodríguez Huéscar. La innovación metafísica de Ortega. Biblioteca Nueva, Madrid, 2002, p. 388. 
jan esa primitiva dualidad funcional y mutual [...] en que el vivir se resuelve» ${ }^{17}$. Dicho de otro modo: no podemos pensar en el yo y la circunstancia como elementos con entidad propia y separada, la vida no es en ningún caso la suma de dos elementos. "Yo» $y$ «mundo» son realidades radicadas, instancias, "funciones reciprocantes $»^{18}$ de una única realidad primaria y radical que es mi vida, la vida de cada cual. Su mutua interacción podría ser comprendida con claridad si fuésemos capaces de pensar esos términos como verbos y no como sustantivos.

\subsection{Dinámica de la estructura vital: la construcción del mundo}

Abríamos este apartado llamando la atención sobre el carácter dialéctico y complejo de la filosofía orteguiana. Como advierte Rodríguez Huéscar, frente al ser de la metafísica tradicional que es el concepto de mayor abstracción y máxima simplicidad, un concepto estático e intemporal, la vida como realidad radical es el concepto de mayor concreción y complejidad, es dinámico y ocasional ${ }^{19}$. Esta máxima complejidad de la vida se expresa en la recíproca ejecutividad entre el yo y la circunstancia. La dinámica de la estructura de la vida humana se establece en niveles de complejidad creciente que van entretejiendo la trama de la historia.

La tríada alteración-ensimismamiento-acción constituye el primer nivel de interacción entre el yo y la circunstancia: a diferencia de los animales a los que su ser les viene ya dado, el hombre no puede vivir en la pura alteración hacia el mundo puesto que carece de una naturaleza dada. La vida del hombre es siempre un quehacer que requiere un plan de acción, de una estrategia con la que saber a qué atenerse. El trato con las cosas poco a poco permitió al hombre algo de tiempo para cuestionarse el mundo y trazar un plan de acción sobre él. Esta estrategia frente al mundo resultó útil y cada vez ganó más tiempo para sí, para depurar su mapa del mundo. Así surge la cultura/ciencia: como respuesta intelectual y técnica a un problema vital. La cultura es en su origen creación auténtica, auténticas soluciones que brotan de la vitalidad, del contacto directo entre el hombre y la realidad.

El segundo nivel de complejidad implicado en el anterior es el formado por las ideas y creencias. Las creencias son el punto de vista, individual y social, desde el cual interpretamos la realidad, las coordenadas de nuestro mapa del mundo. Cada generación, e incluso cada época, tiene unas determinadas creencias -al margen de nuestra adhesión a ellas- que limitan los márgenes del mundo y configuran tanto los problemas como las soluciones posibles en cada

17. Ibíd, p. 127.

18. Ibíd, p. 154.

19. Cfr. A. Rodríguez Huéscar. La innovación metafísica de Ortega. Biblioteca Nueva, Madrid, 2002, p. 136. 
momento. A diferencia de éstas, las ideas son ocurrencias conscientes, construcciones teóricas que surgen de la duda que generan los huecos de nuestras creencias. «En ellas se trata siempre de sustituir el mundo inestable, ambiguo de la duda, por un mundo en que la ambigüedad desaparece. [...] A este fin ensaya figuras imaginarias de mundos y de su posible conducta en ellos. Entre ellas, una le parece idealmente más firme, y a eso llama verdad $»^{20}$. Cada uno de nosotros nace y vive desde unas creencias concretas y a partir de ellas surgen las ideas que van modificando nuestra percepción del mundo. El juego entre ideas y creencias es el motor del desarrollo de la cultura.

Las creencias no siguen un patrón de progreso indefinido sino que cíclicamente entran en crisis restableciendo el contacto entre el hombre y su circunstancia. Este es el tercer nivel de complejidad de la dinámica de la vida humana: la estructura de las crisis históricas. Cada generación encuentra al nacer una cultura ya hecha y la desarrolla haciéndola más compleja. Puesto que los hombres heredan ya las soluciones culturales sin haber antes experimentado los problemas que las generaron, la inercia vital les lleva a aceptar el mundo sin ponerlo en cuestión. Así pues, entre el hombre y la realidad se interpone todo un repertorio de productos culturales que, si bien hunden sus raíces en creencias firmes, generan unos frutos cada vez más alejados de las necesidades vitales que las originaron. La cultura, que comenzó siendo un instrumento para tratar con la realidad, se complica y sobrecarga hasta un punto en que el hombre llega a sentirse ahogado por su contorno cultural. El hombre culto vive una vida inauténtica porque su fe en el mundo es una fe inerte, vacía de toda vitalidad. Frente al desconcierto que esta nueva situación provoca, el hombre busca una respuesta inmediata y subvierte los valores de la vieja cultura esperando que la negatividad se convierta así en beneficio. Esta reacción extrema es un síntoma claro de las crisis históricas: lo mismo se ensalza como se niega el elemento aglutinador de la cultura -ya sea el lógos, Dios o la ciencia-. En cualquier caso, el fracaso de ese desesperado intento prepara al hombre para la verdadera conversión.

Al igual que en el origen el hombre se sentía ahogado frente a las cosas y necesitó crear cultura para tratar con ellas, en los periodos de crisis históricas el hombre se ve asfixiado frente a la cultura y necesita retomar el contacto consigo mismo para que su trato con la realidad recobre su sentido. Pero, cuando esto sucede, no vuelve a un estado primitivo, ahora el hombre tiene historia. Cuando empieza de nuevo a construir el mundo, ya no está sólo frente a las cosas, le acompañan todos los hombres que fue y todos los mundos que ya no pueden ser. El hombre -tanto en su dimensión vital como histórica- proyectará mundos en vista a la circunstancia y a sus experiencias pasadas, creará nuevas fórmulas que superen las limitaciones del pasado. Se trata una vez más de un

20. 1941 Ideas y creencias, op.cit, V, p. 671. 
movimiento dialéctico de ensayo y error en el que toda experiencia pasada -individual o colectiva- se integra en el presente para crear futuro.

Sirva este rodeo por los conceptos básicos del raciovitalismo histórico como un preámbulo necesario antes de afrontar directamente el tema que nos ocupa, puesto que la reflexión de Ortega sobre la ciencia emana directamente de ellos. A continuación veremos la relación entre ciencia e historia a través del análisis orteguiano del nacimiento y desarrollo de la razón científica.

\section{La ciencia moderna}

Está claro que Ortega no fue el primero en señalar las insuficiencias de la razón científica. Desde Nietzsche hasta Heidegger pasando por Husserl o Spengler, la percepción de estar viviendo un tiempo de transición era palpable en el ambiente de su tiempo. A mi juicio, el valor del análisis orteguiano de la modernidad estriba en haber comprendido que ninguna posición es definitiva y que para dar un paso hacia adelante era necesario encaramarse a los hombros de la historia.

Cada momento presente está compuesto por una mezcla de libertad y destino: la libertad es el futuro, aquello que queremos llegar a ser y el destino está escrito en nuestra historia, en todo aquello que ya hemos sido. El presente se le presenta a Ortega como un gran interrogante, pero para poder orientarse necesita saber qué hay en su presente de necesidad, esto es, de historia. Por lo tanto, para saber por qué se ha agotado el modelo de racionalidad moderna es necesario retrotraerse hasta el momento de su nacimiento.

\subsection{Origen: Galileo y Descartes}

En su obra En Torno a Galileo, Ortega explica cómo la razón moderna germina tras la gran crisis de la razón teológica medieval que, como todas las crisis históricas, se produjo por una progresiva complicación de la cultura que acabó por cortar el vínculo entre el hombre y su circunstancia. El mal Ilamado Renacimiento fue un periodo de tentativas y barruntos, tuvimos que esperar hasta Galileo y Descartes para ver el verdadero renacer del hombre a una nueva concepción del cosmos y de sí mismo. Ellos fueron los primeros en sentir con claridad las urgencias de su tiempo. La nueva mirada sobre lo real, que va a fundar la ciencia moderna, va a coincidir en ambos autores: consiste en priorizar el pensamiento sobre la experiencia. Con la nuova scienza se abrirán las puertas del siglo XVI a la Edad Moderna. Esta nueva disciplina intelectual ganará autonomía frente a las formas de conocimiento tradicionales hasta el punto de consolidarse como único modelo y referente del Saber hasta nuestros días.

\section{A. Galileo}

Como decíamos unas líneas más arriba, la historia no da saltos, cada giro en el drama de la historia es el resultado de la combinación de creencias que se 
mantienen y de otras nuevas que emergen. Pues bien, en el caso de la razón moderna a la concepción metafísica de la materia heredada de la antigüedad se le añade la creencia firme en la prioridad de la razón sobre los hechos, que en el caso de Galileo va a cristalizar en la matematización de la naturaleza. Uno de los resultados de este cóctel histórico es el cambio en la concepción del movimiento: ya no se trata de atender a las causas del movimiento en la sustancia como ocurría en la física aristotélica, a partir de ahora se tratará de medir el movimiento en cuanto fuerza. La nueva ciencia se define desde sus comienzos como mensuración. El oficio del científico no es, pues, observar la naturaleza sino descifrar el lenguaje del cosmos mediante la medición matemática de los fenómenos físicos. Galileo es el modelo del científico, diseccionó los fenómenos físicos en elementos más sencillos y nos proporcionó una analítica del movimiento que generó una nueva visión de un mundo unitario y homogéneo. El éxito social y la consolidación de la ciencia como modelo de racionalidad hasta nuestros días se debieron principalmente a dos factores: el método analítico-experimental y su aplicabilidad técnica.

EL NUEVO MÉTODO: Ortega señala con tino que, al contrario de lo que tradicionalmente se piensa, la gran aportación metodológica de la ciencia experimental no fue el experimento sino el análisis deductivo. Cuando Galileo interpretó el plano inclinado como una caída, estaba construyendo leyes a priori sobre el comportamiento ideal de los fenómenos que después contrastó con los fenómenos reales. La analítica del movimiento y la física en general es «un saber a priori, confirmado por un saber a posteriori $»^{21}$. Esto supone que la nueva ciencia nace con un doble criterio de certeza: los fenómenos no sólo responden al análisis conceptual sino que pueden ser verificados por la observación empírica.

APLICABILIDAD TÉCNICA: el conocimiento científico no sólo es superior por su método, también lo es por su utilidad práctica. La ciencia permite el dominio de la naturaleza según la necesidad o el capricho de los hombres. La Europa del XVII es el tiempo del mecanicismo y de la burguesía, el mundo es considerado como una gran máquina que el hombre puede conocer y dominar. El hombre moderno siente interés por el dominio de la naturaleza que la nueva ciencia ofrece. Más allá de la contemplación, el burgués se caracteriza por su imperación sobre el mundo; quiere hacer el mundo a su imagen y semejanza, quiere poseerlo y transformarlo según su conveniencia. De ahí su apoyo incondicional a la nueva ciencia. "La física cobró un prestigio sin par porque de ella emanaban la máquina y la medicina» ${ }^{22}$.

En resumidas cuentas: Galileo inaugura la ciencia como disciplina autónoma que debe su autonomía a la superioridad de su método y al apoyo social

21. 1932 Goethe desde dentro, op. cit. V, p. 236.

22. 1930 ¿Por qué se vuelve a la filosofía?, op. cit. IV, p. 327. 
derivado de su ventajosa utilidad técnica. A partir de este momento la física va a convertirse en el arquetipo del conocimiento y el método analítico en el método por excelencia. El cambio más importante respecto al modelo anterior es que parte de la prioridad del pensamiento sobre los hechos: el conocimiento es una construcción a priori confirmada por la experiencia. El tecnicismo y la ciencia van a consolidarse como disciplinas independientes y pasarán a formar parte del modo de ser del europeo hasta nuestros días. Querámoslo o no, ése es nuestro modo de estar en el mundo.

\section{B. DESCARTES}

Aunque el nuevo modo de pensar que inicia Descartes se caracteriza por su afán de alejarse del escolasticismo y comenzar desde supuestos nuevos, podemos adivinar en su filosofía las mismas creencias que operaban en la ciencia galileana: la prioridad de la razón sobre la experiencia y la herencia metafísica clásica.

PRIORIDAD DE LA RAZÓN SOBRE LA EXPERIENCIA: tanto el método de Galileo como el de Descartes se asientan sobre una nueva concepción del conocimiento. El pensamiento, en lugar de hacerse ideas sobre lo que las cosas son, construye modelos ideales a los que el mundo debe ajustarse. El método analítico-experimental se basa en la creencia en la matematización de la naturaleza: si los fenómenos se rigen según leyes geométricas, la pura razón es capaz de deducir a priori su comportamiento en un modelo ideal. El método cartesiano es paralelo a este planteamiento: la razón pura guiada por un método matemático puede alcanzar el saber universal.

Para Ortega la mayor evolución de la modernidad consistió en haber disuelto la categoría de sustancia en la de relación ${ }^{23}$. El conocimiento deja de ser conocimiento de sustancias para centrarse en las relaciones entre dichas sustancias. Estas relaciones pueden ser conocidas a través de la razón deductiva. Por lo tanto, el método apropiado para hallar conocimiento fiable es el de la aritmética y la geometría, que como sabemos se basan en el método axiomático deductivo, de modo que fijando unos pocos axiomas se puede deducir de ellos el resto del sistema, y del mismo modo podemos partir de cualquier teorema y utilizar la deducción lógica para llegar hasta los axiomas fundamentales. Descartes buscó mediante la intuición intelectual los primeros axiomas o verdades que se presenten a la mente con claridad y distinción, ya que a partir de ellos podía establecer cadenas deductivas de conexiones evidentes. Esto es, el saber universal.

Al cambiar la concepción del conocimiento, también cambia la idea de la «verdad». Frente a los griegos, que buscaban desvelar el ser de las cosas (aletheia), Descartes no busca cosas sino certezas, claridad y distinción, que son cualidades

23. Cfr. 1916 Personas, obras, cosas, op. cit. II, p. 66. 
que no están en las cosas mismas sino en nuestro pensar sobre ellas. La verdad pasa de ser una cualidad de la sustancia a ser una cualidad del pensar. El cambio de la verdad ontológica a la epistemológica implica que la filosofía que hasta entonces había sido estudio del Ser, esto es, metafísica, pasa a ocuparse del «pensar del Ser», acaba el realismo y comienza el reinado del Pensamiento ${ }^{24}$.

HeRENCIA METAFísiCA: Según Ortega, Descartes va a hacer una acertada crítica al realismo en cuanto que niega la primacía ontológica del mundo y defiende la subjetividad, pero al mismo tiempo su propuesta filosófica va a ser deudora de la ontología que critica al mantener los mismos supuestos: a) que lo real es absoluto e independiente y b) que el ser posee una realidad sustantiva. No en vano afirma Ortega que "la misma idea de "cosa" resume una completa metafísica $»^{25}$. El filósofo madrileño advierte del error de Descartes, cuando al encontrar el cogito como primer principio indubitable de su filosofía, en lugar de afirmar «el pensamiento existe» presupuso que bajo ese pensamiento debía haber un «yo pensante» que poseía efectiva realidad y que el pensar era mero atributo de esa sustancia. Este paso del «cogitatio est» a la «res cogitans» es para Ortega un salto ilegítimo que tiene su fundamento en una creencia heredada de la antigüedad: la concepción substancialista del ser. Al igual que Aristóteles, Descartes va a suponer que lo que hay tiene que ser una entidad o cosa y que ésta debe tener un carácter objetivo.

En resumen: a pesar de su talante renovador la modernidad nació bajo los auspicios de los conceptos eleáticos y esto marcó irremediablemente su destino. A continuación veremos cómo el desarrollo y la aplicabilidad de la racionalidad científica llevó al hombre a encarar su mirada al futuro forjándose así la creencia en el progreso indefinido.

\subsection{El desarrollo de la razón científica}

\section{A. Culturalismo, positivismo y utopismo}

Como sabemos, toda cultura nace del contacto directo con la vitalidad de un pueblo, pero su desarrollo complica sus fundamentos y aleja al hombre de las urgencias de las que brotó. Esto precisamente es lo que encuentra Ortega en su presente, el ensayo racionalista ha llegado a su fin, el cumplimiento de los principios modernos ha conducido al agotamiento de la razón pura. El afán idealista por hacer que lo ideal imperase sobre lo real ha llevado a hipostasiar la razón pura aislándola de su verdadero origen, la vitalidad humana. La complicación de la razón moderna ha dado lugar a lo que Ortega denomina «cultura-

24. Cfr. 1947 La idea de principio en Leibniz, op. cit. IX, p. 1.093.

25. 1932 Principios de metafísica según la razón vital. op. cit. VIII, p. 625. 
lismo» o «beatería de la cultura». El positivismo decimonónico es el resultado de haber pasado de una «cultura para la vida» a la «vida para la cultura».

La confianza ilimitada en la razón pura, unida a la constatación de sus avances, ha llevado al hombre a vivir durante los últimos siglos desde la fe en el progreso indefinido. El hecho es que el siglo XIX vivió de una fe viva en la ciencia, ésta no sólo representaba el único saber legítimo, sino que se convirtió en la guía para el progreso social, político y moral de la humanidad hasta el punto de hacer de la ciencia una verdadera religión. Es lógico que en este contexto las ciencias, y sobre todo la física, aspirasen a tener la total hegemonía del saber. Todas las ciencias querían traspasar los límites de su destino, vivían enajenadas, anhelaban convertirse en algo que no eran. La biología quería ser física, la matemática renegaba de la intuición y quería ser pura deducción conceptual, incluso la teología quería llegar a ser una ciencia humana y racional. En lugar de centrarse en los límites de su objeto y acomodar a él su método y razón, todas las ciencias quisieron ser física y guiarse por la razón físico-matemática. De ahí que Ortega diga que el siglo XIX es el «gran siglo bizco», en el que cada ciencia miraba con un ojo a su terreno y con el otro miraban con envidia a la física intentando emularla. Ni siquiera la filosofía escapó del «imperialismo de la física» y de ahí que el positivismo sea una extraña filosofía antifilosófica.

Esta idolatría de la ciencia que Europa ha profesado durante el último siglo también tiene su reflejo en la consideración del hombre de ciencia. El imperialismo de la física va unido al «terrorismo de los laboratorios». El científico, especialista en su minúscula porción del universo, tiende a imponer su autoridad en cualquier otro terreno de la vida pública. Pero, como sabemos, el especialista es precisamente eso: un especialista en lo suyo, pero un ignorante en lo demás. Así pues, el hombre de ciencia actual es el prototipo del hombre-masa porque la ciencia moderna y su especialismo han hecho de él un bárbaro ${ }^{26}$.

Ortega criticará duramente que la creencia en el progreso indefinido y el presupuesto de que todo lo real es racional convirtieron a la ciencia en la forma más extrema de utopismo. La razón científica sólo se ocupa de aquellos problemas que pueden ser resueltos por el método, pero cree poder resolver cualquier otro tipo de problema y pospone la solución de aquellos que no se adaptan al método a las «calendas griegas». Esta convicción no sólo afecta a las cuestiones estrictamente científicas sino que se ha extendido a todos los ámbitos de la vida humana. De tal modo que los asuntos más humanos, como la moral, quedan aplazados a un futuro utópico donde serán resueltos por el saber universal. Mientras tanto, la vida queda en suspenso sin una verdad firme sobre la que orientarse.

26. Cfr. «La barbarie del especialismo» en La rebelión de las masas. 1930 op. cit. IV, pp. 441-446. 
Desde la perspectiva de las crisis históricas podríamos considerar el cientifismo decimonónico como una etapa de extremismo científico, de irreflexiva confianza en la ciencia del mismo modo que el goticismo lo fue respecto a la fe escolástica. En ambos casos, cuando una creencia se convierte en una fe inerte se produce un último movimiento excesivo e irracional por el que el espíritu humano intenta aferrarse a esa creencia que declina. Siguiendo la lógica de las crisis históricas Ortega tiene motivos para pensar que el positivismo es el canto de cisne de la edad moderna cuya agonía es anunciada por la crisis de la racionalidad científica.

\section{B. CRISIS DE LA RACIONALIDAD CIENTíFICA}

Paradójicamente, la ciencia es la única instancia de la modernidad que no ha fracasado en sus propósitos. Es más, el desarrollo de la ciencia moderna ha superado con creces las expectativas que se depositaron en ella. Sin embargo, al igual que en la política, el arte o la filosofía, el siglo XX ha dejado al descubierto la inconsistencia de sus cimientos y su incapacidad para dar cuenta de los problemas humanos. Ortega advierte que el hombre del siglo XX no puede seguir en el positivismo, pero tampoco podrá vivir sin la ciencia. La razón de la quiebra de la razón científica es que ésta ha querido extralimitarse y convertirse en legisladora de la vida. Por eso, la crítica de Ortega no pretende en ningún caso negar la razón pura, su objetivo es redimensionarla frente a la vida para que coja fuerza y vigor dentro de sus límites. Esto es, convertir la limitación en una virtud.

La modernidad se ha forjado sobre la fe en la razón. Pero no de cualquier tipo de razón, sino sobre aquella capaz de dar sentido a la realidad siguiendo una arquitectura geométrica basada en axiomas y deducciones lógicas. La razón moderna es esencialmente físico-matemática, de tal modo que la física y la lógica han sido los pilares maestros sobre los que se ha asentado todo el edificio moderno desde las ciencias puras hasta la organización social de los Estados. Pero hete aquí que la ciencia de las primeras décadas del siglo XX ha dejado al descubierto las insuficiencias de la razón moderna. Los nuevos avances científicos han dinamitado los cimientos de la razón físico-matemática. Ortega tiene en mente la teoría de la relatividad, el principio de incertidumbre, la mecánica cuántica o el teorema de Gödel. La nueva ciencia no es simplemente un paso más en el progreso de la ciencia moderna, supone una verdadera revisión de los fundamentos de la racionalidad científica hasta el punto de que la física y la lógica han dejado de existir tal y como las conocemos.

La fe en la ciencia ha dejado de estar vigente a causa del reduccionismo de la razón a razón físico-matemática. Una consecuencia de esta mutilación de la razón es que la ciencia también ha quedado reducida a ciencia natural. El racionalismo, el idealismo y más tarde el positivismo han hablado del hombre como un ser de naturaleza inmutable, pero han postergado las cuestiones últi- 
mas a un futuro utópico. Pero resulta que los problemas más importantes, los que afectan al íntimo destino de los hombres, no se adaptan dócilmente al método de la razón físico-matemática. El positivismo se equivocó al renunciar a la dimensión última de las cuestiones humanas e ignorarlas bajo el nombre de «mitos». La filosofía nos aporta el último plano de la perspectiva científica y esto es algo irrenunciable ya que si eliminamos el último plano de una perspectiva -tal como hizo el positivismo con las cuestiones últimas- el que era penúltimo queda convertido violentamente en último plano, configurando así una imagen fraudulenta de la realidad. Esta es la denuncia al imperialismo de la física criticado por Ortega.

Las Ilamadas «ciencias del espíritu» tampoco escaparon al imperialismo de la física y quisieron investigar al hombre con ideas naturalistas, buscaron en él una esencia, quisieron apresar su espíritu pero el hombre no tiene naturaleza, no es una cosa, no responde a las categorías eleáticas que la ciencia maneja. El imperialismo de la física, Ilevado al terreno humano, ha dejado al descubierto las insuficiencias de la razón moderna puesto que «lo humano se escapa a la razón físico-matemática como el agua por una canastilla ${ }^{27}$. El hombre no es un ser, es un drama, un puro acontecer en la coexistencia entre el yo y su circunstancia. De ahí que la razón moderna haya fracasado y la fe en la ciencia se haya convertido en una fe inerte.

Queda claro que la razón moderna ha llegado a su ocaso, tanto por la crisis en sus fundamentos físicos y lógicos como por su incompetencia frente a los problemas humanos. Pero esta constatación no debe confundirnos respecto a la valoración que Ortega tiene de la ciencia moderna: la ciencia -al igual que el liberalismo- forma parte de lo que somos. La ciencia es la función más fundamental de nuestra civilización, de ahí que la autenticidad del hombre europeo no puede dar la espalda a los principios que han posibilitado su existencia. Estamos hechos de nuestro pasado y por eso mismo lo que seremos en el futuro no puede volver a ser lo que ya fuimos, pero estará determinado por ello. Porque fuimos modernos ya no lo seremos más, pero nuestro pasado es la única herramienta que poseemos para proyectar el porvenir. El agotamiento de la razón científica no significa el fin de la ciencia. La cuestión es: ¿qué hay en la nueva ciencia que ha nacido con el siglo XX que supera las limitaciones del modelo moderno?

\section{La ciencia del siglo XX desde la perspectiva de la razón vital}

La crisis de los fundamentos ha quebrado los cimientos de la racionalidad científica y ha dejado entrever al hombre que la razón pura es sólo una isla en un océa-

27. 1941 Historia como sistema, op. cit. V, p. 57. 
no de irracionalidad ${ }^{28}$. Es lógico que en este escenario el hombre de su tiempo se sienta como un náufrago, sin ninguna creencia firme que le sostenga. Este naufragio de la vitalidad europea no es sentido por Ortega como una limitación sino como una virtud, una oportunidad para revitalizar las creencias. Por fin el hombre se ha sacudido siglos de Cultura y ha vuelto a tomar contacto con la incertidumbre, que es la materia prima de la vida. Por fin queda el alma franca para una nueva sensibilidad caracterizada por la alegre aceptación de lo real, la creatividad, la higiene de los ideales y la oposición a todo tipo de idealismo. Estos principios son las insignias del quehacer filosófico de Ortega y coinciden con la actitud, métodos y resultados de la nueva ciencia abanderada por Einstein, de ahí que la postura del filósofo frente a la ciencia del siglo XX sea ciertamente esperanzadora.

\subsection{La afirmación de los propios límites}

La crisis de los fundamentos no es simplemente una operación de derribo de los presupuestos científicos que han quedado obsoletos. No, la crisis de los fundamentos ha redefinido los límites del conocimiento científico y desde la fidelidad a su propia limitación la ciencia ha salido fortalecida. En este caso han sido los propios científicos quienes han ahondado en la metafísica para reformular los conceptos teóricos sobre los que se asienta la ciencia, ellos -y no los filósofos- han puesto en cuestión la mismísima noción de sustancia y han construido una nueva teoría del conocimiento físico que nos ofrece una visión nueva del cosmos afín con la pluralidad, relacionalidad y complejidad de lo real.

Frente al utopismo propio de la razón moderna, Ortega ve que la nueva generación de científicos como Gödel, Weyl, Bohr, Einstein o Heisenberg ha dado un impulso definitivo a la ciencia que no solamente ha tenido resultados espectaculares sino que ha resituado el papel del conocimiento científico en la esfera de la vida. Frente al imperialismo de la razón positivista, ahora la ciencia no sólo reconoce sus límites sino que hace de ellos su principal virtud: por eso se reconoce como mera teoría del mundo y no pretende dar solución a aquellos asuntos que están más allá de la cuantificación del universo. Por ser teoría, y por lo tanto lenguaje, asume que el conocimiento que tiene del mundo es un conocimiento simbólico, pero no es el propio mundo. A juicio de Ortega, no solamente se reconocen los límites de la ciencia respecto al mundo y respecto a otros tipos de conocimiento sino que también «cada disciplina se encierra dentro de sus propios confines sin pretender dominar al resto ${ }^{29}$. Fren-

28. Esta afirmación no debe confundirnos: en ningún caso se puede filiar a Ortega con el irracionalismo. Recordemos que la vida sin razón no es vivible y la razón, si no está entroncada a la vida de la cual y para la cual surge, está vacía. Tanto el positivismo como el irracionalismo de comienzos del siglo XX son movimientos extremos característicos en las crisis históricas donde lo mismo se afirma como se niega el elemento aglutinador de la cultura que está quebrando.

29. 1930 Vicisitudes en las ciencias, op. cit. IV, p. 293. 
te a la ciencia y el método universal que inauguró la Modernidad, la ciencia del siglo XX aparece como un abanico de disciplinas autónomas donde cada cual trabaja con un objeto y método delimitado. El teorema de la incompletitud de Gödel, el principio de incertidumbre, la mecánica cuántica, la teoría de la relatividad... todas estas innovaciones parten de un sentir común cuya premisa es la aceptación de lo real.

\subsection{La aceptación de lo real}

Decíamos al comienzo de este artículo que la valoración que Ortega hace de la ciencia -en concreto de la física- se genera desde los mismos presupuestos de su filosofía. Si seguimos avanzando en este supuesto vemos que la aceptación de lo real que guía la reflexión orteguiana exige de nosotros que «renunciemos alegremente, valerosamente, a la comodidad de presumir que lo real es lógico y reconozcamos que lo único lógico es el pensamiento ${ }^{30}$. ¿Cómo es esto posible?

Si partimos de la fidelidad a lo que hay, lo que encontramos es la propia vida, que es pura inmediatez, aquí y ahora. Como vimos, la ejecutividad de la realidad primaria no se doblega dócilmente a los conceptos de la ontología tradicional puesto que no tiene carácter sustancial ni accidental. Sin embargo, el hombre necesita saber a qué atenerse y para eso utiliza la razón, que se afana en clasificar y conceptualizar la realidad. Pero ésta no está estructurada según patrones fijos de racionalidad. La razón es «una breve zona de claridad analítica que se abre entre dos estratos insondables de irracionalidad $»^{31}$. Frente a siglos de idealismo, hoy tenemos que asumir -dirá Ortega- que lo único racional es el pensamiento. Esta es la paradoja a la que se enfrenta todo conocimiento, incluida la ciencia: por un lado, la fidelidad a lo real nos muestra la realidad desnuda que es movimiento, finitud, multiplicidad e incertidumbre. Pero Ortega advierte que «la vida sin verdad no es vivible» ${ }^{32}$, no nos es posible vivir en la pura alteridad: necesitamos dar un orden y un sentido a lo real, y para eso la vida cuenta con la razón que se afana en construir certezas mediante sistemas unitarios que nos den seguridad.

Es imposible escapar de esta paradoja onto-epistémica: al querer elaborar una teoría sistemática de la realidad que escape al idealismo, encontramos que toda conceptualización traiciona la multiplicidad de la realidad que pretende atrapar, y sin embargo, nos es imposible renunciar a la unidad del pensamiento. La aceptación de esta paradoja implica graves consecuencias en la consideración de la ciencia:

30. 1941 Historia como sistema, op. cit. VI, p. 62.

31. 1924 Ni vitalismo ni racionalismo, op. cit. III, p. 722.

32. 1934 Prólogo para alemanes, op. cit. IX, p. 148. 
a) Es necesario invertir el papel del método en el proceso del conocimiento: ahora es la realidad y no el método quien guía la investigación. La razón no impone su medida a lo real sino que adapta sus principios formales a las exigencias empíricas. Por lo tanto, la nueva ciencia tiene que contar con la incertidumbre como principio, sin renunciar por ello a su constitutiva sistematicidad.

b) Como consecuencia de lo anterior, un conocimiento sistemático no es el que da respuesta a todo, sino aquel capaz de abrir sus preguntas a la totalidad de lo que hay a sabiendas de que no existen teorías definitivas que queden libres del tribunal de la experiencia. Por lo tanto, toda ciencia $-y$ toda filosofía- que aspire a decir algo sobre la realidad tendrá que reconocerse como un sistema abierto a falsación.

c) A fin de cuentas, la ciencia que se ciña a la realidad sin imponerle a priori sus esquemas explicativos será necesariamente una ciencia del pluralismo.

Falsación, incertidumbre y pluralismo. Éstos son precisamente los atributos de la nueva ciencia del siglo XX. Esta nueva concepción de la ciencia queda resumida por Ortega en el siguiente texto: «El imperativo de pulcritud mental hace que nuestro tiempo parta en toda ciencia -y tal vez no sólo en ciencia- de la pluralidad que es el hecho. La geometría se ha pluralizado; la física de los quanta de Einstein es discontinua y pluralista; la biología se ha instaurado en el pluralismo. Por fin, la historia, en vez de tropezar a la postre como con una roca de irracionalidad, como con un misterio, con la peculiaridad de los pueblos, que son de hecho irreductibles, hace de ella el punto de partida; es decir, toma el hecho según se presenta. [...] La intuición del pluralismo universal, como puro hecho, como fenómeno, es la gran innovación de la cultura europea. A ella se debe que, contrastando con la enorme decadencia de casi todas las demás potencias históricas -economía, política, arte-, la ciencia actual abra infinitas perspectivas y festeje una sin par ampliación de horizontes. Si al analizar la pluralidad que los hechos reales presentan se encuentra en ellos síntomas de una ultrarrealidad unitaria, el triunfo será completo. Porque, en efecto, el pensamiento debe ser unitario. Pero es preciso dejar siempre abierta la posibilidad de que los hechos se nieguen a coincidir con ese ideal de unidad que alienta en el interior del pensamiento ${ }^{33}$; también en la física de Einstein encontramos esa fidelidad a lo real opuesta al apriorismo de la ciencia moderna. Según Ortega, la teoría de la relatividad es el resultado de haber amoldado el método a las exigencias de la realidad y haber antepuesto la experiencia real a cualquier teoría por coherente que resulte. Einstein invierte la relación entre la

33. 1924 Las Atlántidas, op. cit. III, pp. 763-764. 
razón y la observación, ahora es la experiencia la que impera sobre la razón y decide qué teoría casa con los hechos, la geometría se adapta a la física y el espacio al fenómeno corpóreo ${ }^{34}$.

Llegados a este punto nos damos de bruces con una cuestión peliaguda: el empirismo metodológico de corte marchiano convive en Einstein con una concepción pitagórica del cosmos que le llevó a buscar durante toda su vida una teoría unificada del Universo. Según Carlos Madrid, esta contradicción entre el credo epistemológico y el credo metafísico-religioso de Einstein explicaría el desconcierto del científico frente al comentario de Ortega de que acabaría haciendo de la física una matemática ${ }^{35}$, puesto que «Einstein sigue concibiendo que determinamos empíricamente la geometría del mundo, en vez de geometrizar el mundo en función de nuestros intereses científicos» como creía Ortega. La cuestión de fondo es el estatuto de las teorías científicas. A juicio de C. Madrid, Ortega tendría una «concepción de la relatividad como teoría física que impone convencionalmente su geometría al universo, como recurso para describir cómodamente sus características». Mientras que Einstein concebía la relatividad "como teoría física que comporta una fisicación de la geometría, convirtiéndose la geometría del universo en objeto de estudio a la manera que los astros o los electrones lo son ${ }^{36}$.

La tesis que propongo en estas líneas a propósito de esta cuestión es que la aparente contradicción entre el credo epistemológico y las convicciones metafísico-religiosas de Einstein puede ser asumida no como una incoherencia en su labor científica sino como reflejo de la paradoja del conocimiento de la que Ortega era consciente. Ambos autores están marcadamente influidos por Kant, ambos parten de la plena aceptación de lo real y consideran que el conocimiento científico es puro simbolismo, pero ninguno de ellos puede renunciar a la sistematicidad de la razón. El encaje entre los conceptos y la experiencia no deja de ser un misterio para ambos.

Según Ortega la ciencia es el resultado «de una mutua selección entre las ideas puras y los hechos puros $»^{37}$. Los fenómenos son el tribunal ante el que las construcciones teóricas de los hombres rinden cuentas de su utilidad o conveniencia para explicar la realidad. En el mismo sentido, para Einstein la correspondencia entre la teoría y la experiencia sólo puede ser explicada como una milagrosa "armonía preestablecida» puesto que no hay un camino lógico que conduzca de la experiencia a la razón y sin embargo «la experiencia demuestra que de todas las construcciones pensables hay una superior y digna de aten-

34. Cfr. 1930 ¿Por qué se vuelve a la filosofía?, op. cit. IV, pp. 335-336.

35. 1937 Bronca en la física, op. cit. V, p. 431.

36. C. M. Madrid. «A vueltas con Ortega, la física y Einstein», en Revista de Occidente $n^{\circ}$ 294, 2005, pp. 5-20.

37. 1923 El tema de nuestro tiempo, op. cit. III, p. 651. 
ción ${ }^{38}$. En una palabra: aunque existe un salto entre el conocimiento y la realidad, de algún modo los hechos seleccionan las teorías más adecuadas y podemos contar con la fiabilidad del conocimiento.

\subsection{La ciencia es mero simbolismo}

Pese a que las siguientes citas podrían pasar por ser de un mismo autor, lo cierto es que la primera pertenece a Ortega y fue escrita en 1929 y la segunda es de Einstein en 1936. Esta metáfora del guardarropa refleja perfectamente la visión que ambos autores tenían del conocimiento científico.

«Las fichas del guardarropa. Las banderas de los pueblos. La ciencia no es más que correspondencia simbólica. Si se compara el contenido de la física con lo que es el mundo corpóreo no se hallaría apenas similitud. Son como dos idiomas diferentes que permiten únicamente la traducción ${ }^{39}$.

\section{J. Ortega y Gasset.}

«Un adepto de la teoría de la abstracción o de la inducción Ilamará a nuestros estratos "grados de abstracción", pero no considero justificable encubrir la independencia lógica del concepto con respecto a las experiencias sensoriales. No se trata de la relación que existe entre la sopa y el pollo sino, más bien, de la del número del guardarropa y el abrigo $»^{40}$.

A. Einstein.

Como bien apunta C. Madrid «Ortega se mueve en la estela del racionalismo convencionalista que floreció a finales del XIX y comienzos del XX de manos de Poincaré o Duhem ${ }^{41}$. Los conceptos físicos que pretenden describir el mundo son imágenes humanas que el científico inventa para mensurar la realidad y poder manejarse en ella. Ahora bien, que la ciencia se fundamente en conceptos inventados libremente por el hombre, no implica que sus descripciones sean mera fantasía ya que, de algún modo, la experiencia selecciona aquellas teorías que se corresponden con la realidad. La correspondencia entre las teorías y la realidad es la misma que la que hay entre la ficha del guardarropa y el abrigo. Las fichas no se parecen en nada a los abrigos, pero nos proporcionan una información exacta para orientarnos en el ropero del universo y encontrar aquello que buscamos. La precisión y utilidad de la ciencia han dotado a este conocimiento de un valor indispensable para el ser humano. Si bien no es una brújula, es un mapa sin el cual no podríamos sobrevivir.

38. Einstein. Mi visión del mundo. Tusquets, Barcelona, 2008, p. 131.

39. 1929 ¿Qué es filosofía?, op. cit. VIII, p. 258.

40. Einstein. Obra Esencial. Crítica, Barcelona, 2005, p. 246.

41. Carlos M. Madrid. «A vueltas con Ortega, la física y Einstein», en Revista de Occidente $\mathrm{n}^{\mathrm{o}} 294,2005$, p. 7. 
A fin de cuentas - dirá el filósofo- la ciencia emana de la misma fuente que el arte o la poesía, es el "admirable mito europeo» ${ }^{42}$. Frente al imperialismo de la física, que considera que su conocimiento es superior por ser cuantificable y por lo tanto exacto, Ortega advierte que "sólo puede ser exacto lo fantástico ${ }^{43}$ y la física es hija de la fantasía al igual que otros conocimientos sobre el mundo. La realidad no es exacta, pero nuestro conocimiento sobre ella sí debe serlo.

Las teorías y leyes científicas son mapas de la realidad que hacen del mundo un lugar habitable, pero no son la realidad. Lo que la física nos enseña del Universo son sus medidas, por lo tanto, la validez de las verdades físicas queda circunscrita al ámbito de la realidad del cual se ocupan; el ámbito de lo cuantificable. La verdad científica es una teoría sobre el mundo, una pequeña porción de una perspectiva concreta de la verdad. Nada más, pero tampoco nada menos. No es la verdad completa, ni una verdad última, porque el único punto de vista absoluto es el de la vida y la ciencia se mueve necesariamente en el ámbito del lenguaje simbólico y la generalización. La posición de Einstein en este punto es muy similar y también podría leerse en paralelo con los textos sobre el ensimismamiento y alteración:

«El hombre procura formarse una imagen adecuada y fácilmente aprehensible del mundo, con el fin de sobreponerla a la experiencia de la realidad, sustituyéndola hasta cierto punto y grado por ella. Esto hacen, cada uno a su modo, el pintor, el poeta, el filósofo y el investigador de la naturaleza. Hacia esta imagen y su elaboración desplazan lo principal de su vida sensible, buscando así la paz y la seguridad que no pueden encontrar en el círculo demasiado estrecho de su agitada experiencia personal ${ }^{44}$.

Ortega y Einstein comparten una opinión similar sobre el origen del lenguaje: ambos entienden que las palabras son elementos vivos y que constituyen el único puente entre la mente y las cosas. Aunque el origen de las palabras está en las cosas mismas, el uso las ha alejado de su verdadera significación y las ha convertido en monedas desgastadas que han perdido su original valor. La ciencia moderna ganó precisión y claridad al cuantificar los conceptos que describen la realidad, pero con ello se pagó el precio de perder el contacto entre los modelos teóricos y la experiencia sensible y por lo tanto el carácter relacional y perspectivista de lo real.

42. 1928 ¿Qué es la ciencia, qué la filosofía?, op. cit. VIII, p. 274.

43. 1940 Ideas creencias, op. cit. V, p. 671.

44. Einstein. Obra Esencial. Crítica, Barcelona, 2005, p. 130. 
"Se ha incurrido, con el tiempo, en el error de considerar que la necesidad lógica -anterior a toda experiencia- era la base de la geometría euclidiana y del concepto de espacio perteneciente a ella; ese fatal error surgió del hecho de que la base empírica, sobre la cual descansa la construcción axiomática de la geometría euclidiana, cayó en el olvido» ${ }^{45}$.
«Porque lo que tenemos de la cosa, al tener su nombre, es una caricatura: su concepto. Y, si no andamos con cuidado, si no desconfiamos de las palabras, procurando ir tras de ellas a las cosas mismas, los nombres se nos convierten en máscaras que, en vez de hacernos, en algún modo, presente la cosa, nos la ocul$\tan »^{46}$.

La proximidad de Einstein con el convencionalismo de Poincaré también está presente en algunos textos como Física y realidad. Allí Einstein afirma que los conceptos científicos, que son el fundamento teórico de toda ciencia, son invenciones libres que hace la mente a partir de la experiencia sensorial pero que con el tiempo pierden su significación inmediata y ligada a la experiencia en favor de cuestiones pragmáticas. Encontramos un claro ejemplo en su análisis del concepto geométrico de «espacio»: este concepto nace de la experiencia sensorial primaria de las relaciones de posición de los objetos materiales. Nuestra mente, que siempre tiende a la unificación y simplificación de los principios explicativos, pasó de referir el «espacio» a las relaciones de los objetos para darle a este concepto autonomía ontológica como entidad absoluta. "La atrevida noción de "espacio" que precedió a toda la geometría científica, transformó nuestro concepto de las relaciones entre posiciones de los objetos materiales en la noción de posición de esos objetos en el "espacio" ${ }^{47}$.

Resumiendo: tanto la filosofía de Ortega como la física de Einstein siguen la máxima fenomenológica de volver a las cosas mismas, pero en ambos casos el camino hacia las cosas está empedrado de conceptos. A pesar de que el conocimiento nunca puede alcanzar plenamente su objetivo y debe conformarse con ser mera ficha de guardarropa, es posible ser fieles a las cosas mismas volviendo al origen de las palabras.

\subsection{El sentido histórico de la teoría de Einstein}

Bajo el título El sentido histórico de la teoría de Einstein, Ortega disecciona las concomitancias entre la teoría del científico y su propia filosofía. El absolutismo, perspectivismo, antiutopismo y finitismo de la teoría de la relatividad son síntomas evidentes de un cambio histórico en la concepción de la realidad que se extiende a todos los ámbitos de la vida. Para Ortega, el sentido histórico de

45. Ibíd, p. 250.

46. 1943 Epílogo de la Filosofía, op. cit. IX, p. 615.

47. Einstein. Obra esencial. Crítica, Barcelona, 2005, p. 249. La cursiva es nuestra. 
la teoría de Einstein consiste en ser una confirmación de la nueva sensibilidad que se avecina y, por tanto, de su propia filosofía. Los argumentos que da en el apéndice al Tema de nuestro tiempo son más o menos los que siguen:

Según la mecánica clásica de Galileo y de Newton la realidad es absoluta e inconmensurable y nuestro conocimiento de ella es relativo puesto que las determinaciones empíricas (movimiento, situación...) son relativas a un espacio y un tiempo absolutos que nuestro limitado conocimiento nunca puede abarcar. Sin embargo, la física de Einstein invierte estos términos y al negar que el espacio y el tiempo sean absolutos, hace de los datos empíricos la única referencia para conocer la realidad. La realidad no es absoluta sino relativa a la perspectiva espaciotemporal del observador, el punto de vista desde el cual se observa la realidad hace que ésta nos ofrezca un aspecto de sí misma determinado.

$\mathrm{Al}$ contrario que en la física clásica, nuestro conocimiento es absoluto mientras que la realidad tiene un carácter relativo o relacional. El hecho de que todo conocimiento esté mediado por una determinada perspectiva no implica de ningún modo que dicho conocimiento sea subjetivo, pues cualquier espectador en el mismo lugar tendría la misma perspectiva ante la cual la realidad desvelaría su naturaleza objetiva. El espacio y el tiempo vuelven a ser formas de lo real que hacen que cada perspectiva posea valor objetivo ${ }^{48}$.

Puesto que todo conocimiento responde a un punto de vista determinado, no podemos hablar de espacio y tiempo absolutos, ya que no existe ni puede existir una perspectiva absoluta. Espacio y tiempo absolutos son abstracciones a priori que nada tienen que ver con la realidad que se pretende conocer.

Concluyendo, la audacia de Einstein estriba en haber sido capaz de cambiar el enfoque tradicional que soslayaba las dificultades y haberse encarado con ellas, hasta el punto de convertir lo que parecía defecto -la relatividad de todas nuestras medidas- en el fundamento de la nueva física ${ }^{49}$. El carácter relacional de toda medición no implica un conocimiento de la realidad menos fiable. La relatividad de la medición conlleva, desde un punto de vista filosófico, una pérdida de densidad ontológica. El mundo deja de ser absoluto y compacto para ser limitado, fluido y flexible. Así como Galileo se enfrentó a la creencia en la majestad de los cielos en beneficio de la medición, la teoría de Einstein pone entre paréntesis nuestras categorías sobre la realidad para afrontar los acontecimientos desde la pluralidad y relacionalidad.

Esta misma actitud es la que Ortega busca para su propia filosofía: si la limitación del hombre está en la contradicción entre la vida y nuestro intento de teorizar sobre ella, la virtud del hombre consistirá en seguir filosofando y hacer

48. Cfr. 1923 El tema de nuestro tiempo, op. cit. III, p. 647.

49. Cfr. 1931 La redención de las provincias, op. cit. IV, p. 730. 
de la filosofía un sistema, aun sabiendo que toda certeza es una breve isla en la incertidumbre del vivir.

\section{El camino entre la filosofía y la ciencia}

Bajo la premisa de que la concepción orteguiana de la ciencia debe ser leída a la luz del fondo metafísico de su filosofía, hemos tomado esta cuestión como el hilo conductor que nos ha guiado a través de tres estancias interconectadas: la innovación metafísica de Ortega, el desarrollo histórico de la razón moderna y la función de la ciencia como conocimiento simbólico. Ahora ha llegado el momento de recoger el hilo que nos ha traído hasta aquí y desandar el camino entre la filosofía y la ciencia.

Más allá de su acierto o desacierto en sus juicios sobre el fenómeno científico, en esta conclusión quisiera destacar el valor de las coordenadas que mueven el pensamiento de Ortega y que han ido apareciendo en los diferentes apartados de este artículo. Me estoy refiriendo al cambio en la concepción del ser, la apelación a la historia y la audacia de formular un sistema capaz de integrar la contradicción.

- La filosofía de Ortega es en última instancia una revisión rigurosa y profunda de los cimientos de la metafísica tradicional que no se limita a señalar sus deficiencias sino que propone una alternativa que integra la complejidad de lo real sin renunciar a la sistematicidad del conocimiento. Este cambio en la concepción del ser supone un giro copernicano que afecta tanto a la metafísica como a la epistemología puesto que ambas están irremediablemente unidas. Aunque no es este el momento de desentrañar el nudo gordiano que las une, debe quedar claro que la innovación metafísica de Ortega trae consigo una innovación epistemológica que exige una nueva filosofía, una nueva ciencia y un nuevo lenguaje que se adecúen a la nueva realidad. El ser es el objeto común de la ciencia y de la filosofía, pero éste se desvela como una realidad dinámica, compleja, ejecutiva. Como hemos visto en el último epígrafe, esta nueva comprensión de la realidad radical demanda una ciencia -la relativista- y una filosofía -el raciovitalismo- a la altura de los tiempos.

Ahora bien, sin restar un ápice a la originalidad y profundidad de la propuesta metafísica orteguiana, no podemos concluir sin advertir que su intento de hacer del perspectivismo el fundamento gnoseológico de la nueva física de Einstein, al modo que Kant lo hizo con Newton, fue un lugar común entre los filósofos de su tiempo. Así, Bertrand Russell afirmaba en 1926 «Ha existido una tendencia, no rara en el caso de una nueva teoría científica, de que todo filósofo interprete el trabajo de Einstein de acuerdo con su propio sistema metafísico, y que sugiera que el resultado 
es un gran fortalecimiento de las opiniones que el filósofo en cuestión mantenía previamente ${ }^{50}$.

- Por otra parte, frente a quienes sitúan a Ortega en la vanguardia de la postmodernidad tenemos que recordar que para el filósofo madrileño en la historia no hay saltos ni cambios bruscos, no es posible saltar fuera de la propia sombra. Por esa razón el análisis que hace Ortega de la modernidad no es un simple enfrentamiento o crítica sino que busca comprender la historia de las creencias y salvar lo que en ellas hubo de auténtico para enlazarlo con su tiempo presente e ir configurando su filosofía. La fidelidad a las cosas mismas implica necesariamente la fidelidad a la historia que nos constituye. En eso consiste la razón histórica. La historia, tanto individual como social, es a fin de cuentas una cuestión de ensayo y error: para vivir los hombres hacemos teorías, fantaseamos mundos posibles y Ilamamos verdad a aquella interpretación que nos parece más firme hasta que queda refutada por la experiencia. Lo que hoy somos es el resultado de lo que otros han sido, y hacia dónde vayamos en el futuro dependerá de cómo seamos capaces de comprender la dinámica que nos ha traído hasta el presente.

Si bien es cierto que la reivindicación de la historia ejerció gran fuerza en los intelectuales de finales del XIX y principios del XX, la razón histórica de Ortega va mucho más allá del historicismo y propone una reforma total de la historiología que escapa igualmente al dogmatismo y al relativismo, haciéndola emerger de la propia vida humana. Por lo tanto su propia filosofía intenta aunar lo necesario y lo temporal entroncándose con la tradición moderna desde la propia conciencia de ser una filosofía circunstancial y por lo tanto provisional.

- A fin de cuentas, Ortega nos ofrece una modo de pensar flexible y poroso capaz de integrar la complejidad y contradicción propia de la realidad. Así, es capaz de ofrecernos una visión que, sin renunciar a la ciencia, deja al descubierto sus insuficiencias y paradojas internas. El hombre que seremos no podrá vivir de espaldas a la ciencia, pero deberá asumir que se trata de un quehacer humano que brota al igual que la razón poética o la razón pictórica de la creatividad humana y cuya función es la de crear metáforas que nos proporcionen visiones útiles del mundo.

Como decíamos al comienzo, este trabajo parte de la convicción de que la reflexión de Ortega sobre la ciencia no es propiamente una filosofía de la ciencia. Ortega es un filósofo, a secas. Y no es lícito presentarle como un precursor de la filosofía de la ciencia. Sin embargo, al lector avezado no se le habrán

50. B. Russell citado por J. M. Sánchez Ron. «Einstein y la filosofía del siglo XX» en Arbor no 728 (2007) Madrid, p. 847. 
escapado los numerosos puntos de conexión entre la visión orteguiana del la ciencia y las teorías de Popper, Kuhn, Feyerabend o Lakatos: el análisis histórico de la práctica científica, la naturaleza y función de los paradigmas, la correlación entre la experiencia y la teoría, la falsación, la importancia de las creencias en el contexto de descubrimiento, el debate entre instrumentalismo o realismo, la crítica al método, la reivindicación de la creatividad en el proceso del conocimiento, la estetización de la epistemología... Todos estos conceptos, que hoy en día son moneda común en la filosofía de la ciencia, aparecen ya en la reflexión de Ortega como consecuencia del su raciovitalismo histórico. Su mirada atenta al «signo de los tiempos» le permitió entrever cuestiones entonces incipientes, pero que permanecen hoy en plena vigencia. $Y$ no solamente en lo que a la ciencia se refiere, hoy seguimos teniendo la convicción de vivir en un tiempo de crisis y ya nadie espera el resurgir de los grandes relatos que nos salven del naufragio en el que consiste el drama del vivir.

En definitiva: los aciertos que puede haber en la interpretación orteguiana de la ciencia se deben directamente al conjunto de su filosofía que emana a su vez de una actitud vital que hemos intentado esbozar en estas páginas. Siguiendo el proverbio popular que dice que es mejor enseñar al hambriento a pescar que darle peces, podemos concluir que el legado de la filosofía de Ortega no reside tanto en las respuestas que ofreció a los problemas de su tiempo como en el enfoque desde el cual su pensamiento es capaz de abrir preguntas a las cuestiones que acucian nuestro presente.

La sistematicidad de la filosofía de Ortega reside precisamente en su preguntar, porque cada interrogante lleva en sí un abanico de posibles respuestas que, aun siendo contradictorias, delimitan un contorno en el que la realidad se muestra en su auténtica complejidad. Las preguntas que los hombres son capaces de hacerse en cada época emanan directamente de la fidelidad a su punto de vista. Dibujar ese contorno complejo y paradójico es hoy más que nunca el tema de nuestro tiempo. 